Journal of the Scholarship of Teaching and Learning, Vol. 19, No. 3, June 2019, pp.1-15.

doi: 10.14434/josotl.v19i2.23732

\title{
"Do we really need this class?": Former K-12 Teachers Transitioning to Teaching as University Faculty
}

\author{
Margarita Jimenez-Silva \\ University of California Davis \\ mjimenezsilva@ucdavis.edu \\ Pamela Kulinna \\ Arizona State University \\ kulinna@,asu.edu \\ Anna Montana Cirell \\ Arizona State University \\ acirell@asu.edu \\ Matt Balmaseda \\ Arizona State University
}

\begin{abstract}
The focus of many Ph.D. programs in research-intense universities across disciplines is to prepare its graduate students to enter the professoriate with the skills needed to be successful in meeting institutional research expectations. Although most tenure-track positions include teaching responsibilities, few programs prepare faculty for teaching at the post-secondary level. As faculty at a research-intensive university, we developed a pilot course focused on preparing future faculty to develop the knowledge, confidence, and understanding of usefulness of constructs related to teaching in university classrooms. Overall, all ten participants found the course useful and provided feedback that will inform future iterations of the course. Misalignment of course expectations are discussed as are constructs perceived as most helpful to their future teaching.
\end{abstract}

Keywords: college faculty, graduate education, college teaching, pedagogy.

The focus of many Ph.D. programs in research-intense universities across disciplines is to prepare its graduate students to enter the professoriate with the skills needed to be successful in regard to meeting institutional research expectations. Although teaching and service commitments are commonly part of the expectation as a new assistant professor, these two areas are rarely systematically addressed through coursework nor are graduate students mentored when assigned teaching assistantships. Boden, Borrego and Newswander (2011) claim that "higher education institutions in which graduate students are trained are ill-equipped to facilitate interdisciplinary research, teaching, and other aspects of interdisciplinary graduate training" (p. 742).

Furthermore, only about $26 \%$ of Ph.D. students in the United States move into tenured or tenure-track positions and even then, the time to get into these positions can take much longer than Ph.D. candidates expected (Gould, 2015). Many graduates find themselves taking positions in which their primary responsibility is to teach while they seek out tenure-track positions. There are few resources that are available to guide future faculty through the process of transitioning from teaching at K-12 setting to the university classroom. Although many Ph.D. students in colleges of education may have experience teaching in K-12 settings, there is an adjustment in terms of pedagogy, student issues, and university expectations and oversight that needs to be taken into consideration. Furthermore, working with university colleagues presents its own sets of challenges and opportunities 
different from K-12 settings. For faculty from culturally and linguistically diverse backgrounds, the challenges can be even greater (Hernandez, Murakami-Ramlho, \& Rodriguez, 2015).

\section{Ecological Model}

Our study is broadly framed under sociocultural theory, which asserts that learning is an inherently social activity (Rogoff, 1990; Vygotsky, 1978). Briefly described, sociocultural processes center on socially-mediated understandings and rely on interactive and situated learning to push development forward (Driscoll \& Driscoll, 2005). Herein, the instructor's role is to engage learners and their learning partners in socially-organized practices relevant to their culture. The learner then interacts with social environment (inclusive of the instructor, peers, and artefacts) with the end goal of more culturally-appropriate thinking abilities, skilled use of cultural tools, and greater awareness of one's own thinking. Given this, sociocultural practices of college teaching become widespread and efficacious only with support from the broad learning environment on the grounds that these practices fulfill the academy's recurring and time-sensitive cultural and social needs (Katz, 2010).

As an analytic and theoretical tool to deconstruct the socio-cultural components of college teaching, we borrow from Bronfenbrenner's (1979) Ecological Systems Theory. Sociocultural learning is supported by the interrelationship(s) among different social, cultural, legal, political, and economic institutions, as well as the influential practices and protocols that develop around them. As such, the ecological systems framework presents the concrete analytic needed to outline this interrelationship of various contexts. From there, grounding research within this framework helps to disentangle the impact of multiple interactions occurring on and through specific systems as one develops socioculturally.

Bronfenbrenner (1979) delineated various systems (microsystem, mesosystem, exosystem, the macrosystem, and the chronosystem) of influence. To understand the complex, mutually shaping influences across interrelated environments in this analysis, we streamline the interacting systems to include only the microsystem, mesosystem and macrosystem. Described concisely, the microsystem concerns the environment, of direct contact, closest to the individual, while the mesosystem involves the interconnections across different parts of a person's microsystem. The macrosystem, which evolves slowly over time, subsumes all other levels and concerns the larger impact of the environment or community, its underlying cultural norms, political context, and economic arrangements.

The ecological levels interact to influence a mature progression from the inside out. For example, choosing the university as the microsystem, students socialize to the art and science of teaching through strengthening their core values and developing a discipline-specific identity, while establishing relevant practices specific to internal structures. This then allows them to advance to the next level (mesosytem) where they must perform appropriately with various colleagues, administrators, and departments across their university microsystem. With adequate interpersonal skills, students can then move on to the macrosystem level to enact change on a larger societal or cross-institutional scale.

\section{Related Research}

There is a gap in the literature and professional trade books in training education faculty and all future faculty for teaching at the university level. One identified text addresses general teaching practices for all faculty (e.g., Svinicki \& McKeachie, 2014); however, it is less appropriate for future faculty with a teaching background. Within our own college, many of our doctoral students have

Journal of the Scholarship of Teaching and Learning, Vol. 19, No. 3, June 2019.

josotl.indiana.edu 
experience in the K-12 school system while others enter our Ph.D. program with no classroom experience. Education faculty, in particular, need to learn how to balance teaching time with research time and service time (which is different from K-12 teaching) as well as developing teaching skills/experiences in higher education contexts with diverse student populations and unique challenges. Students and new faculty members may be currently receiving an unintended message (personal communication with student in program on September 15, 2016) that teaching is less important than other responsibilities of faculty members.

If graduate students are being socialized into a culture in which teaching should be prioritized behind research and service, this poses a challenge to preparing graduate students for their future roles in the university classroom during a time when their time and energy is already limited. In order to shift the culture, institutions need to have faculty who are exceptionally passionate about the topic in question (Boden et al., 2011), teaching in our context. Graduate students and professors established in their academic careers have commented on the lack of attention to their development as educators. Austin and McDaniels (2006) found that graduate students and criticisms of their training generated five recommendations, one of them being the need for developmentally-oriented teaching opportunities.

Socialization of graduate students into higher education, the discipline of education in our case, is a useful and commonly used framework for understanding graduate students experiences (Golde, 1998). Socialization, as it applies to graduate students, has been defined by Weidman, Twale and Stein (2001, p. iii) as "the processes through which individuals gain the knowledge, skills, and values necessary for successful entry into a professional career requiring an advanced level of specialized knowledge and skills." According to Golde (1998), it spans from moving from a novice to a full-fledged member of a professional community. Furthermore, Tierney (1997) argues that an organization's culture "teaches people how to behave, what to hope for, and what it means to succeed or fail" (p. 5).

Scholars proposed various stages involved in doctoral student socialization to future faculty (Austin \& McDaniels, 2006; Braxton \& Baird, 2001; Gardner, 2007; Golde, 1998; Lovitts, 2001; Sweitzer, 2009). Research on doctoral education indicates that the doctoral student university experience is the first stage of socialization to the faculty career (Austin, 2002; Austin \& McDaniels, 2006). At the university microsystem, students begin their new program by learning the language of a particular discipline, building a new identity, and entering into the discourse, or ways of being (Gee, 2012), of the academy. The development of relationships with peers and faculty within the mesosystem is particularly important to the socialization stages (Sweitzer, 2009). Austin (2002) also found that at the macrosystem level, adjusting to the changing broader societal expectations of the academy is also a necessary stage for traditional and nontraditional faculty.

\section{Microsystem: Socialization to Disciplinary Structures of the University}

From the first year in a graduate program, students' experiences provide important lessons for how they should perform as researchers, educators, and citizens within their institutional communities (Neumann, 2009). Scholarship on the acclimation of future faculty to the university microsystem focuses on identity development (Austin \& McDaniels, 2006; Sweitzer, 2009), professional development programming (Austin, 2002; Kondakci \& Haser, 2012), as well as the changing structural nature of interdisciplinarity (Gardner et al., 2014; Holley, 2010).

For identity development, Austin and McDaniels (2006) propose that preparations for future professoriate include specific abilities, knowledge, appreciations, and skills related to academia. Proper knowledge acquisition can build a sense of professional identity, when doctoral

Journal of the Scholarship of Teaching and Learning, Vol. 19, No. 3, June 2019. josotl.indiana.edu 
students learn the discipline-specific language as well as the history, defining issues, and the belief systems of the field. A second core component in identity development calls for the investment of self in the form of time, energy and money. Lastly, is the need for involvement, where commitment actualizes through participation in scholarly activities such as professional conferences, college teaching assistantships, and research projects. Sweitzer (2009) asserts that these experiences socialize doctoral students to adopt certain professional roles and inquiry practices available within the university structure to approach the broad disciplinary issues. Viewed in this way, socialization occurs through a great range of experiences which influence a trajectory that is neither linear nor stable, but instead dynamic and varied.

Also stressed in the literature is the importance of professional development programming for socialization. Within these formal and structured programs, future faculty learn rules and expectations of the workplace (Kondakci \& Haser, 2012). Noting the scarcity of developmentally appropriate professional development, Austin (2002) underscores the need for systematic guidance on faculty tasks, such as advising, building a curriculum, committee work, navigating ethical dilemmas, and community outreach. Other professional development programs for future faculty involve teaching certification programs and competitive grant writing workshops (Vanderbilt Center for Teaching, 2017, https://cft.vanderbilt.edu/). Also needed is an understanding of how academic works for tenure-track faculty, inclusive of faculty governance hierarchies, the influence of administration, as well as the relative weight of teaching, research and service (Tierney \& Bensimon, 1996).

As the disciplinary nature of academia changes, future faculty must adjust to interdisciplinary perspectives and approaches (Gardner et al., 2014; Holley, 2010). Given socialization frameworks have mostly focused on traditional conception of disciplines as siloes, new models are needed for gauging experiences within the increasing number of interdisciplinary doctoral programs. At first, interdisciplinarity can be viewed as a paradox within historical and popular conceptions dominating higher education (Holley, 2010). Doctoral programs have long existed with the sole purpose of producing scholars with an extensive depth of expert knowledge within their discipline. While disciplines should not necessarily be seen as monolithic entities bereft of diverse scholarship (Donald, 2002; Lattuca, 2001; Toma, 1997), working and thinking within specific knowledge field aligns future faculty within a specific disciplinary community of practice (Lave \& Wenger, 1991). However, interdisciplinary programs expect future faculty to work and research across multiple communities of practice. Additionally, doctoral students must understand how to integrate knowledge when addressing research problems. Given the challenge when balancing a depth of disciplinary knowledge within the breadth of interdisciplinary approaches (Holley, 2010), socialization processes must overcome institutional barriers to collaborative space, departmental engagement, and research paradigm politics (Bogden et al., 2011).

\section{Mesosystem: Mentoring/networking Models of Socialization}

The primary means by which graduate students are being socialized is through their interactions with professors and other students (Lovitts, 2001). Most studies address the impact of these developmental interactions through mentoring (Cawyer, Simonds, \& Davis, 2002; Schrodt, Cawyer \& Sanders, 2003), social capital (Niehaus \& O’Meara, 2015), or social network analysis (Baker \& Lattuca, 2010; Pifer \& Baker, 2013; Rawlings \& McFarland, 2011).

Briefly defined, mentoring, as a form of socialization, acts as a communicative relationship wherein a senior scholar supports the career development of a junior faculty (Schrodt et al., 2003). A future faculty's ability to adjust to life in academia is predicated upon the bidirectional strength between the newcomer's network of colleagues and the colleagues' willingness to mentor (Cawyer et

Journal of the Scholarship of Teaching and Learning, Vol. 19, No. 3, June 2019.

josotl.indiana.edu 
al., 2002). This back-and-forth interpersonal connection can allow for formal and informal opportunities to practice professional identity and perform certain roles in appropriate ways. In this supportive capacity, tenured faculty professionally coach and psychosocially validate the junior faculty through acts of friendship and acceptance (Cawyer et al., 2002). Mentors are particularly important when they can navigate the junior faculty through the murky and stressful waters of the tenure process (Alexander, 1992; Cawyer et al., 2002; Tierney \& Bensimon, 1996). However, practical challenges exist that may lessen the influential power of mentorships in academia. Because of the nature of academia's high work load, faculty mentors are often unavailable or inconsistent (Cawyer et al., 2002). To combat this tendency, Cawyer et al. (2002) argue against simply encouraging informal mentoring to suggest well-developed programs with formal assigning of mentors.

Understanding interpersonal bonds as a form of social capital, Niehaus and O’Meara (2015) research the role of on and off-campus professional networks for future faculty. According to Bourdieu (1986), social capital highlights the role of an individual's social networks, group membership, connections and/or supportive relations that lend power through information, influence, and allies. Seen this way, the social capital gleaned from others can emerge and permeate from individuals or from larger communities. Social power can often increase the professional agency of a junior faculty, when they leverage strategic perspectives or actions that propel them forward professionally (O’Meara, Campbell, \&Terosky, 2011). Challenges of relying on social capital for career advancement is that supportive networks take time to develop and the resultant social power evolves slowly (Niehaus \& O’Meara, 2015).

Social network analysis calls attention to the complex connections occurring between doctoral students' networks and their learning experiences, career advancement, and professional identity development (Baker \& Lattuca, 2010; Pifer \& Baker, 2013; Rawlings \& McFarland, 2011). Social network approach is beneficial in that it provides a structural framework for exploring the role of multiple relationships as well as tracing the flow influence (Baker \& Lattuca, 2010; Rawlings \& McFarland, 2011). Likewise, all networks are viewed within the mentoring role. This relationship constellation yields a variety of long-term benefits, such as retention, professional development, and identity formation (Dobrow \& Higgins, 2005; Higgins, 2000; Higgins \& Thomas, 2001; Sweitzer 2008), and short-term boosts, including greater career satisfaction and stronger intentions to persist towards tenure (Baugh \& Scandura, 1999; Higgins, 2000; Higgins \& Thomas, 2001; van Emmerik, 2004). Studies show that strategic awareness and internal power relations (between genders and authority positions) often dictate the functional patterns emerging from the networked flow of influence (Rawlings \& McFarland, 2011).

\section{Macrosystem: Future Faculty Socialization as a Cultural Process}

Due to increasing numbers of culturally and linguistically diverse faculty entering academia, the literature indicates the pressing need to frame faculty socialization as a cultural process (Bogler, \& Kremer-Hayon, 1999; Jayakumar et al., 2009; Johnson, 2001; Rhoads, \& Valadez, 2016; Tierney \& Rhoads, 1994). Amid this acclimation to broader societal values, other higher education literature foregrounds the pressure to internalize culturally imposed gender norms (Lester, 2008). However, the recent literature casts a compelling claim that socialization can be framed as bidirectional process-meaning that as newcomers learn what is expected of them, they can also exercise the power to enact, discard, and/or reshape problematic organizational and professional norms (Sule, 2014). In this way, socialization as a cultural process can be managed for future empowerment (Tierney \& Rhoads, 1994).

Due to the difficulty in understanding and then navigating the particular culture of their host institution (Johnson, 2001; Tierney \& Rhoads, 1994), faculty members' beginning years are often the

Journal of the Scholarship of Teaching and Learning, Vol. 19, No. 3, June 2019. josotl.indiana.edu 
most stressful. Scholars believe that successful adjustment within the final stages of socialization reflects a deep engagement/internalization to the cultural configurations junior faculty search out and find (Trowler \& Knight, 1999). However, the effort required to align with the cultural norms, expectations, and needs of their new organizations, is not equal across all junior faculty. According to Sule (2014), academic socialization originates from and reproduces a legacy of race and gender exclusion. Frequently, traditional professional development fails to sufficiently address how minority faculty negotiate institutional norms when defining their professorial role. Rhodes, Ochoa and Ortiz (2012) propose that culturally and linguistically diverse (CLD) doctoral students have particular developmental needs. Though not necessarily linear or prescriptive, socialization as a cultural process may require the following phases: Honeymoon Phase - exhilaration, hopefulness; Culture Shock Phase - confusion, discouragement; Adjustment Phase - understanding of new culture, acceptance of differences; balancing and blending native and new; and Acceptance Phase - identification with new culture.

Additionally, organizational discourses and social practices extend beyond race and ethnicity to also perpetuate gender appropriate roles for men and women (Lester, 2008). From their study of promotion and tenure practices, Tierney and Bensimon (1996) discovered that women faculty feel pressured to enact "mom" and "smile" work, perform a caring and nurturing role, extinguish conflict, while also avoiding confrontation. Further, women are expected to participate in service activities at higher rates than their male counterparts in order to perform the "glue work" of the academic department and maintain universities functioning (Eveline, 2004; Lester, 2008; Tierney \& Bensimon, 1996). Women also report the unstated obligation to reinforce gender stereotypes by advising a disproportionate share of students and fulfill the "emotional work" needed amongst students and colleagues (Acker \& Feuerverger, 1996; Bird, Litt, \& Wang, 2004; Knights \& Richards, 2003; Tierney \& Bensimon, 1996). While female faculty understand this work as essential and advantageous for institutional culture, they do not assume it beneficial for their career advancement (Knights \& Richards; Lester, 2008). Not conforming to the expected behavior for their sex or gender, LGBT faculty face added stress when navigating heteronormative privilege (Dozier, 2012). Oftentimes, LGBT faculty report their social validity denied through invisibility, misrecognition, and discrimination.

\section{Context and Purpose}

To fill needed gaps in the literature, we used sociocultural and ecological systems theory to enact, through practice, recommendations for developmentally-oriented teaching. At our institution in the U.S. Southwest, we were invited to design and implement an elective course within the college of education aimed at preparing future faculty to teach in a university setting. Through our planful actions, we sought to uncover the necessary pedagogical structures to be built and/or improved. Currently, the Graduate School in our University offers support to future faculty through Preparing Future Faculty (PFF) and according to its website, it is recognized nationally for its professional development program for doctoral students, MFA students and postdocs who intend to pursue a faculty position. Admission to the PFF two-semester, one credit per semester course is limited in enrollment (currently 56). Teaching is addressed as one of the roles of becoming a future faculty member. However, it is stated clearly on the website that although teaching is covered, it is only one part of the agenda. Typically in the PFF, only one of 12 sessions focuses on teaching.

Our efforts were not necessarily to duplicate this program, but to surpass it in breadth and depth through a more sociocultural application of college teaching across interacting ecological systems. The purpose of this research project was to study individual's perceptions of and the

Journal of the Scholarship of Teaching and Learning, Vol. 19, No. 3, June 2019. josotl.indiana.edu 
processes related to learning to teach at the university/college level. With a group of third year doctoral students, this study addressed the following questions: 1) How do participants perceive their knowledge, confidence, and usefulness of constructs around teaching at the post-secondary level? 2) What aspects of a pilot course do students find most and least helpful in their preparation to teach at the post-secondary level?

\section{Methods}

To answer our research questions, we employed an exploratory mixed methodology design (Creswell \& Clark, 2007) with data collected from four sources. From this multi-faceted approach, we felt we could more effectively uncover the complex learning experiences taking place across interacting ecological systems. As discussed by Creswell and Clark (2007), an exploratory mixed methods design sequentially builds upon an initial phase of mostly qualitative data analysis through the subsequent collection and analysis of quantitative data. In our follow-up quantitative phase, then, we explored potential change in personal development from pre-to-posttest. We leveraged these quantitative scores to ground our preliminary qualitative findings and construct a more complete understanding of broad relationships between students and their university microsystem as well as patterns across learning ecologies. Hence, through this mixing of research methods, no form of qualitative or quantitative data were given more precedence or weight, as the integration of their analysis could serve both research questions and enhance the overall findings.

\section{Participants}

The participants in this study were third year doctoral students at a university in the Southwestern USA participating in the first year of this study and at the onset of their preparation to teach at the post-secondary level. Participant demographics included female $(n=7)$ and male $(n=3)$ graduate students who identified as having ethnic backgrounds as Caucasian $(n=8)$, Latino/a $(n=1)$, and South Korean $(n=1)$. Four graduate students indicated that they had no K-12 teaching experience, while the other students reported years of teaching experience at the K-6 level as one to 20 years $(M=4.1$, $S D=6.5)$ and at the 7-12 level as two to ten years $(M=3.6, S D=3.6)$.

\section{Instruments}

Methods of data collection bring their own flaws/biases to the research (Maxwell, 2012), and though not intended to confirm findings, triangulating student feedback data against quantitative pretestposttest scores helped to counterbalance, cross-check, and broaden our mixed methods data set.

\section{Qualitative Data Sources}

Data were collected through three qualitative sources: (a) four formal semi-structured interviews (spread out across the academic year), each lasting 20-40 minutes (with one participant only completing three interviews); (b) class observations with field notes and (c) document analysis of completed course assignments, in-class presentations, and other materials (e.g., guest presenters notes and handouts) etc. During the interviews, graduate students were asked to self-rate their preparedness to teach at the post-secondary level, using a scale of 1 not at all prepared to 10 extremely prepared. Interviews were recorded and later transcribed verbatim. 


\section{Quantitative Pre/Post Surveys}

The fourth data source was a quantitative pre and post survey based on the Bronfenbrenner Ecological Systems (1977) along with the Knowledge-Confidence-Usefulness instrument (KCU) first used by Barton-Arwood, Morrow, Lane, and Jolivette (2005) and more recently used by Lane et al. (2015). The topics covered in the course were identified from the content covered in the two employed textbooks (Gray \& Drew, 2012; Svinicki \& McKeachie, 2014) and a course reading (Bain, 2004) to track perceptions related to their knowledge, confidence; and the usefulness of the experiences designed to help prepare them for teaching at the higher education level. There were 24 topics identified that were covered in the course based on the course developed from the two aforementioned textbooks including: (a) use of eportfolios; (b) understanding university culture; (c) meeting a class for the first time; (d) understanding academic rank; (e) models of best teaching; (f) teaching styles; (g) coteaching; (h) working with Academic Associations and Teaching Assistants; (i) technology and social media in teaching; (j) online teaching; ( $\mathrm{k}$ ) student engagement and motivation; (l) learning styles and cognition; (m) physical activity breaks/movement differentiation in the classroom; (n) preventing and addressing faculty and student issues; (o) issues of cultural difference; (p) FERPA issues; (q) dealing with controversial topics; (r) balancing research, teaching and service; (s) active learning; $(\mathrm{t}$ ) balancing work and home life; ( $\mathrm{u}$ ) being a good citizen, (v) negotiating teaching loads and responsibilities; (w) transferring skills; and (x) ethics in higher education. Each of the aforementioned topics had three questions addressing: (1) knowledge, (2) confidence, and (3) usefulness of the perception items (i.e., $24 \times 3$ or 72 items). The instrument had a scale ranging from zero to three. The instrument design and use of these three questions on each topic were based on the KCU instrument first developed by Barton-Arwood et al. (2005). For each course topic, graduate students were asked the same questions for each of the three outcome areas (knowledge, confidence, and usefulness). For example, "please rate your knowledge using the criteria below: Knowledge: 0 - I have no knowledge of this concept or strategy. 1 - I have some knowledge of this concept. 2 - I have more than average knowledge of this concept or strategy. 3 - I have a substantial amount of knowledge of this concept or strategy."

\section{Data Analysis}

Qualitative data sources were analyzed using constant comparison and analytic induction methods to identify and extract common themes across participants and data sources during the year (LeCompte \& Preissle, 1993). In a preliminary sense-making data reduction strategy, the researchers borrowed from the current literature on ecological understandings of doctoral socialization to future faculty to code along the following principles: interdependence, feedback, cycling of resources, and adaptation (Wielkiewicz \& Stelzner, 2005). In addition to these process-oriented themes, the researchers generated a separate coding scheme to map the three levels of interacting systems across our adaptation of Bronfenbrenner's ecological theory. Several techniques were used to support the trustworthiness of the data, including data triangulation, peer review, member checking, and a search for negative cases.

Descriptive statistics were used to analyze all of the survey data (means, standard deviation, frequencies). Summative variables were created for the 3 outcome areas of knowledge, confidence and useful for the pre and post results from graduate students. Internal Consistency Reliability analyses were performed across all perception items (e.g., 72) for the pretest and for the posttest. 


\section{Results/Discussion}

This mixed methods study allowed for the multi-faceted examination of the effectiveness of a pilot course in positively impacting doctoral students' developmental socialization to future faculty. Our group of graduate students, with the majority having been K-12 teachers, had high self-ratings of their current abilities to teach at the post-secondary level ranging from 6-8 with 10 being extremely confident [with one student who did not self-rate]. The results related to graduate students' postsecondary teaching perceptions included the themes of being confident, having the potential to be effective at the post-secondary level, and a mismatch between expectations and course design. These themes along with salient course topics are discussed below.

First, graduate students discussed their confidence as post-secondary teachers. Ester stated, for example, "I don't really foresee any problems with it. I like teaching. I generally have a very good rapport with students and I think as long as I'm teaching some kind of content that I know enough about, I'll be fine." Second, graduate students also talked about their potential to be effective postsecondary teachers, Bill mentioned "...I think I have all the basic building blocks in place, but from being a teacher I know that there's no substitute for experience. I feel confident that I can get up to a 9 or a 10, but it's going to take some time of course, just actually being in the trenches and doing the work...there's always more to learn."

The final major theme that emerged from the qualitative data sources was a mismatch between expectations of the course and what was accomplished by the end of the semester. Interview data and field notes revealed that students had expected to know what specific course they would be teaching the following semester early in the course. Consequently, they assumed that most of the class would be devoted to developing their own course syllabus reviewing and/or developing their own course readings and assignments. As course designers, that was never our intended goal. Scheduling issues did not allow for assignment of courses to doctoral students as instructors until very late in the semester. One of the course assignments required that the graduate students shadow an instructor/professor in a course they would be interested in teaching. Nine of ten students expressed that it would have been helpful to know what course they would be teaching in order to determine which instructor/professor to shadow.

Addressing the second research question (from interviews, field notes and document analyses), the course assignment identified as most useful was developing a teaching philosophy statement. In interview 4, after their semester of teaching and one semester after initially writing their philosophy statement, eight of the ten participants stated that their basic philosophies had not changed and that having had time to reflect on their teaching philosophy had made them more effective instructors. Regarding what students found the least helpful in the pilot course, seven of the ten participants did not find the course readings helpful nor useful and strongly suggested that we eliminate the course texts. This was most strongly expressed by those participants who had substantial teaching experience. In addition, although the participants generally stated that they had benefitted from the guest speakers, they expressed frustration at the limited time that was devoted to opportunities to interact with one another in order to share and discuss course topics and completed assignments. They also felt that they had not had adequate time to interact with us as seasoned professors with substantial teaching experience.

Internal Consistency Reliabilities for the perceptions items were alpha $=.93$ and .95 for the pre and post survey items, respectively. Descriptive statistic results suggested that graduate students' perceptions of the knowledge, confidence and usefulness of the topics covered in the course were quite positive. For the pre survey, they rated $64 \%$ of the items with a 2 or 3 (or better than average or highly for knowledge, confidence and useful). This number increased overall for the posttest to $86 \%$. The topic five items across all three areas were all related to usefulness and included: (a) Negotiating

Journal of the Scholarship of Teaching and Learning, Vol. 19, No. 3, June 2019.

josotl.indiana.edu 
Teaching Loads and Responsibilities, (b) Preventing and Addressing Faculty and Student Issues, (c) Student Engagement and Motivation, (d) Understanding University Culture, and (e) Ethics in Higher Education.

This ecological pattern of student learning and development can be illustrated through the emergent process model of Chi and colleagues (2012). In this model, the three components are the pattern level of overall perceived dynamics (macro level), the individuated university agents/students within the socialization process (micro level), and the social subgroups into which the agent/student network (meso level). Defining characteristics of the emergent process are that the interactions of the entire collection of academic actors (e.g., students, faculty, and administrators) cause the pattern, all interactions serving local goals and have equal status within the pattern, students can behave in nonmatching or disjointed ways, and the pattern emerges from the collective summing of local interactions at each point in time (Chi et al., 2012). Though all individual action is goal-oriented and coordinated via implicit cues and subtle signals, unique patterns of self-organizing behaviors emerge without blueprint or intention. Similar to this emergent process model, many of the doctoral students could not predict how their individual actions and interactions would impact the larger pattern of activity on the macro level. Yet, when they could practice leadership at higher levels, they developed greater awareness and purpose regarding their individual actions, which in turn increased through sheer stimulation of interactivity. Mixed methods inferences can be developed which posit that it is the high interactivity and emergent co-construction of leadership practices across an ecology of socialization that leads to the highest growth and sense of efficacy among individual doctoral students.

\section{Conclusions}

To summarize, all data sources provide evidence that doctoral students preparing to teach at the postsecondary level can benefit from a course focused on teaching. Their preparation in a researchintensive doctoral program should include an opportunity to develop as course instructors, given that most tenure-track positions in education include teaching responsibilities that are evaluated as part of progression towards tenure. The results of this study have implications for theory, research, and doctoral education.

\section{References}

Acker, S., \& Feuerverger, G. (1996). Doing good and feeling bad: The work of women university teachers. Cambridge Journal of Education, 26, 401-422. https://doi.org/10.1080/0305764960260309

Austin, A. E. (2002). Preparing next generation faculty: Graduate school as socialization to the academic career. The Journal of Higher Education, 73(1), 95-122. https://doi.org/10.1080/00221546.2002.11777132

Austin, A. E., \& McDaniels, M. (2006). Preparing the professoriate of the future: Graduate student socialization for faculty roles. In J. C. Smart (Ed.), Higher education: Handbook of theory and research, XXI (pp. 397-456). Dordrecht, The Netherlands: Springer.

Bain, K. (2004). What makes great teachers great? The Chronicle of Higher Education, 50(31), B7.

Baker, V. L., \& Lattuca, L. R. (2010). Developmental networks and learning: Toward an interdisciplinary perspective on identity development during doctoral study. Studies in Higher

Journal of the Scholarship of Teaching and Learning, Vol. 19, No. 3, June 2019.

josotl.indiana.edu 
Education, 35, 807-827. https://doi:10.1080/03075070903501887

Barton-Arwood, S., Morrow, L., Lane, K. L., \& Jolivette, K. (2005). Project IMPROVE: Improving teachers' ability to address student social needs. Education and Treatment of Children, 28, 430-443.

Baugh, S. G., \& Scandura, T. A. (1999). The effect of multiple mentors on protégé attitudes toward the work setting. Journal of Social Behavior and Personality, 14(4), 503.

Bird, S., Litt, J., \& Wang, Y. (2004). Creating status of women reports: Institutional housekeeping as "women's work." NWSA Journal, 16, 194-206.

Boden, D., Borrego, M., \& Newswander, L. K. (2011). Student socialization in interdisciplinary doctoral education. Higher Education, 62(6), 741-755. https://doi:10.1007/s10734-0119415-1

Bogler, R., \& Kremer-Hayon, L. (1999). The socialization of faculty members to university culture and norms. Journal of Further and Higher Education, 23(1), 31-40. https://doi.org/10.1080/0309877990230103

Bourdieu, P. (1986) The forms of capital. In J. Richardson (Ed.) Handbook of Theory and Research for the Sociology of Education (New York, Greenwood), 241-258.

Braxton, J. M., \& Baird, L. L. (2001). Preparation for professional self-regulation. Science and Engineering Ethics 7, 593-610. https://doi.org/10.1007/s11948-001-0016-8

Bronfenbrenner, U. (1979). The ecology of human development: Experiments by nature and design. Cambridge, MA: The Harvard Press.

Cawyer, C. S., Simonds, C., \& Davis, S. (2002). Mentoring to facilitate socialization: The caseof the new faculty member. International Journal of Qualitative Studies in Education, 15(2), 225242. https://doi.org/10.1080/09518390110111938

Chi, M. T. H., Roscoe, R. D., Slotta, J. D., Roy, M., \& Chase, C. (2012). Misconceived causal explanations for emergent processes. Cognitive Science: A multidisciplinary journal, 36(1), 161. https://doi:10.1111/j.1551-6709.2011.01207

Creswell, J. W., \& Clark, V. L. P. (2007). Designing and conducting mixed methods research (p. 275). Thousand Oaks, CA: Sage publications.

Donald, J. (2002). Learning to think: Disciplinary perspectives. San Francisco: Jossey-Bass.

Dobrow, S. R., \& M. C. Higgins (2005). Developmental networks and professional identity: A longitudinal study. Career Development International 10(6/7), 567-83.

Dozier, R. (2010). The experiences of LGBT faculty at Western Washington University: A report submitted to the LGBT Advocacy Council. Retrieved from http://www.wwu.edu/eoo/docs/ExperiencesofLGBTFacultyatWWU.pdf 
Driscoll, M. P., \& Driscoll, M. P. (2005). Psychology of learning for instruction. Boston, MA: Pearson.

Eveline, J. (2004). Ivory basement leadership: Power and invisibility in the changing university. Crawley, Western Australia: University of Western Australia Press.

Gardner, S. K. (2007). I heard it through the grapevine: Doctoral student socialization in chemistry and history. Higher Education, 54, 723-740. https://doi.org/10.1007/s10734-0069020-x

Gardner, S. K., Jansujwicz, J. S., Hutchins, K., Cline, B., \& Levesque, V. (2014). Socialization to interdisciplinary: Faculty and student perspectives. Higher Education, 67(3), 255-271.

Gee, J. P. (2012). Situated language and learning: A critique of traditional schooling. New York: Routledge.

Golde, C. M. (1998). Beginning graduate school: Explaining first-year doctoral attrition. In M. S. Anderson (Ed.), The experience of being in graduate school: An exploration. San Francisco: Jossey-Bass.

Gould, J. (2015). How to build a better PhD. Nature, 528, 25-28. https://doi:10.1038/528022a.

Gray, P., \& Drew, D. E. (2012). What they didn't teach you in graduate school: 299 helpful hints for success in your academic career. Sterlinng, Virginia: Stylus.

Hernandez, F., Murakami-Ramlho, E., \& Rodriguez, G. M. (Eds.). (2015). Abriendo puertas, cerrando heridas (Opening doors, closing wounds): Latinas/os Findings work-life balance in academia. Charlotte, NC: Information Age Publishing.

Higgins, M. C. (2000). The more, the merrier? Multiple developmental relationships and work satisfaction. Journal of Management Development 19, 277-96. https://doi.org/10.1108/02621710010322634

Higgins, M. C., \& Thomas, D. A. (2001). Constellations and careers: Toward understanding the effects of multiple developmental relationships. Journal of Organizational Behavior, 22(3), 223-247. https://doi.org/10.1002/job.66

Holley, K. (2010). Doctoral student socialization in interdisciplinary fields. In S. K. Garnder \& P. Mendoza, (Eds.), On becoming a scholar: Socialization and development in doctoral education (97-112). Sterling, VA: Stylus.

Jayakumar, U. M., Howard, T. C., Allen, W. R., \& Han, J. C. (2009). Racial privilege in the professoriate: An exploration of campus climate, retention, and satisfaction. The Journal of Higher Education, 80(5), 538-563. https://doi.org/10.1080/00221546.2009.11779031

Johnson, B. J. (2001). Faculty socialization: Lessons learned from urban black colleges. Urban Education, 36(5), 630-647. https://doi.org/10.1177/0042085901365007 
Katz, V. S. (2010). How children of immigrants use media to connect their families to the community: The case of Latinos in South Los Angeles. Journal of Children and Media, 4(3), 298-315. https://doi.org/10.1080/17482798.2010.486136

Knights, D., \& Richards, W. (2003). Sex discrimination in UK academia. Gender, Work and Organization, 10, 213-238. https://doi.org/10.1111/1468-0432.t01-1-00012

Kondakci, Y. \& Haser, C. (2012). Alignment of the forman and informal support in the socialization of the faculty members. Procedia - Social and Behavioral Sciences, 46, 4394-4398. https://doi:10.1016/j.sbspro.2012.06.261

Lane, K. L., Oakes, W. P., Powers, L., Diebold, T., Germer, K., Common, E. A., \& Brunsting, N. (2015). Improving teachers' knowledge of functional assessment-based interventions: Outcomes of a professional development series. Education and Treatment of Children, 38(1), 93-120. https://doi:10.1353/etc.2015.0001

Lattuca, L. R. (2001). Creating interdisciplinarity: Interdisciplinary research and teaching among college and university faculty. Nashville, TN: Vanderbilt University Press.

Lave, J., \& Wenger, E. (1991). Situated learning: Legitimate peripheral participation. Cambridge University Press.

LeCompte, M. D., \& Preissle, J. (1993). Ethnography and qualitative design in educational research (2nd ed). San Diego, CA: Academic Press.

Lester, J. (2008). Performing gender in the workplace: Gender socialization, power, and identity among women faculty members. Community College Review, 35(4), 277-305. https://doi.org/10.1177/0091552108314756

Lovitts, B. E. (2001). Leaving the ivory tower: The causes and consequences of departure from doctoral study. Lanham, MD: Rowan \& Littlefield Publishers.

Maxwell, J. A. (2012). Qualitative research design: An interactive approach. Thousand Oakes, CA: Sage.

Neumann, A. (2009). Professing to learn: Creating tenured lives and careers in the American Research University. Baltimore, MD: Johns Hopkins University Press.

Niehaus, E., \& O’Meara, K. (2015). Invisible but essential: The role of professional networks in promoting faculty agency in career advancement. Innovative Higher Education, 40(2), 159171.

O’Meara, K. A., Campbell, C.M., \& Terosky, A. (2011). Living agency in the academy: A conceptual framework for research and action. Charlotte, NC: Paper presented at the annual meeting of the Association for the Study of Higher Education.

Pifer, M. J., \& Baker, V. L. (2013). Managing the process: The intradepartmental networks of earlycareer academics. Innovative Higher Education, 38, 323-337. https://doi: 10.1007/s10755- 
014-9302-7

Rawlings, C. M., \& McFarland, D. A. (2011). Influence flows in the academy: Using affiliation networks to assess peer effects among researchers. Social Science Research, 40, 1001-1017. https://doi:10.1016/j.ssresearch.2010.10.002

Rhoads, R. A., \& Valadez, J. R. (2016). Democracy, multiculturalism, and the community college: A critical perspective. Abingdon, United Kingdom: Routledge.

Rhodes, R. L., Ochoa, S. H., \& Ortiz, S. O. (2012). Assessing culturally and linguistically diverse students: A practical guide. New York, NY: Guilford Press.

Rogoff, B. (1990). Apprenticeship in thinking : Cognitive development in social context. New York: Oxford University Press.

Schrodt, P., Cawyer, C. S., \& Sanders, R. (2003). An examination of academic mentoring behaviors and new faculty members' satisfaction with socialization and tenure and promotion processes. Communication Education, 52(1), 17-29. New York, NY: Guilford Press. https://doi.org/10.1080/03634520302461

Sule, V. T. (2014). Enact, discard, and transform: A critical race feminist perspective on professional socialization among tenured Black female faculty. International Journal of Qualitative Studies in Education, 27(4), 432-453. https://doi.org/10.1080/09518398.2013.780315

Svinicki, M. D., \& McKeachie, W. J. (2014). McKeachie's teaching tips: Strategies, research, and theory for college and university teachers (14th Ed.). Belmont, CA: Wadsworth.

Sweitzer, V. B. (2009). Towards a theory of doctoral student professional identity development: A developmental networks approach. The Journal of Higher Education, 80(1), 1-33. https://doi.org/10.1080/00221546.2009.11772128

Tierney, W. G. (1997). Organizational socialization in higher education. The Journal of Higher Education, 68, 1-16. https://doi.org/10.1080/00221546.1997.11778975

Tierney, W. G., \& Bensimon, E. M. (1996). Promotion and tenure: Community and socialization in academe. Albany: State University of New York Press.

Tierney, W. G., \& Rhoads, R. A. (1994). Faculty socialization as a cultural process: A mirror of institutional commitment (ASHE-ERIC Higher Education Report No. 93-6). Washington, DC: GeorgeWashington University, School of Education and Human Development.

Toma, J. D. (1997). Alternative inquiry paradigms, faculty cultures, and the definition of academic lives. The Journal of Higher Education, 68(6), 679-705. https://doi.org/10.1080/00221546.1997.11779006

Trowler, P., \& Knight, P. T. (2000). Coming to know in higher education: theorizing faculty entry to new work contexts. Higher Education Research \& Development, 19(1), 27-42. https://doi.org/10.1080/07294360050020453 
Vanderbilt Center for Teaching. (2017). Retrieved from https://cft.vanderbilt.edu/

Van Emmerik, I. J. (2004). The more you can get the better: Mentoring constellations and intrinsic career success. Career Development International, 9(6), 578-594. https://doi.org/10.1108/13620430410559160

Vygotsky, L. S. (1978). Mind in society: The development of higher psychological processes. Cambridge: Harvard University Press.

Weidman, J. C., Twale, D.J., \& Stein, E. L. (2001). Socialization of graduate and professional students in higher education-A perilous passage? ASHE-ERIC Higher Education Report No. 28(3). Washington, DC: The George Washington University, School of Education and Human Development.

Wielkiewicz, R. M., \& Stelzner, S. P. (2005). An ecological perspective on leadership theory, research and practice. Review of General Psychology, 9(4), 326-341. https://doi:10.1037/10892680.9.4.326 